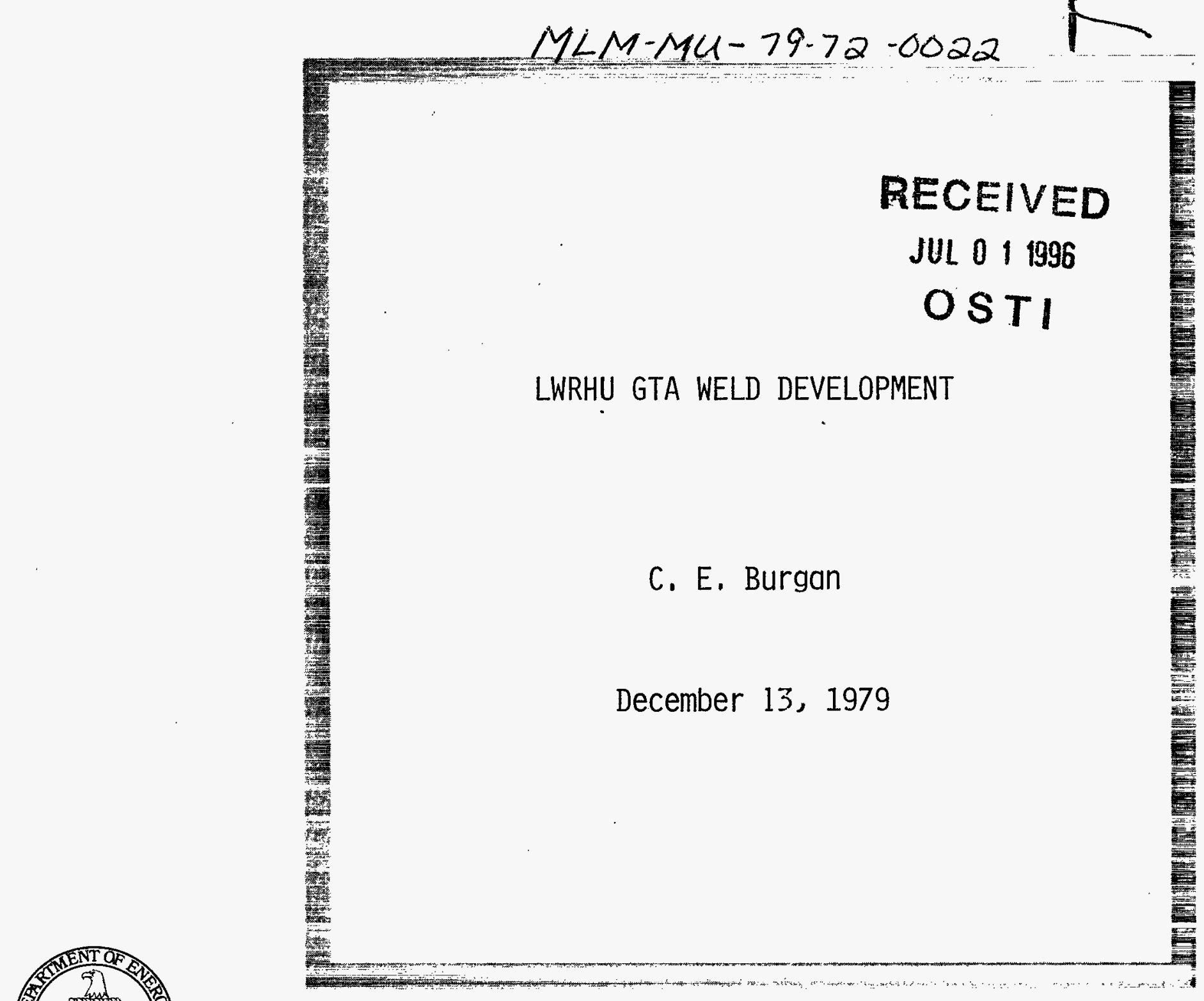

Monsanto

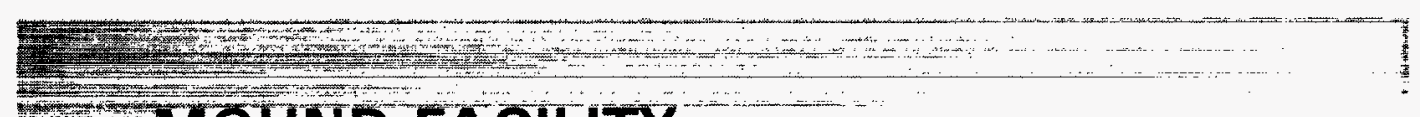

2. Mamisburg. Onio 45342

intorated by

- MONSANTO RESEARCH CORPORATION

to subsidiany of Monsanto Company

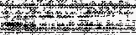

for the

O. S. DEPARTMENT OF ENERGY

Contract No. DE-ACO4-76-DPOOOS3

Fon Contract No. DE-ACO4-78-DPODOS

intwa 


\section{LWRHU GTA WELD DEVELOPMENT}

C. E. Burgan

Weld Development Engineer

\section{INTRODUCTION}

Nineteen. LWRHU Development WeTds have been made. Welds WD-1 through WD-4 were made early in the program to obtain preliminary joint design data. Welds WD-5 through WD-10 were made with the vertical leg of the shim located toward the closure end cap. A decision was made to locate the shim with the vertical leg on the fuel side of the capsule; therefore, the data obtained on the above capsule welds will not be included in this report. A tantalum pellet machined to the configuration of the fuel pellet was placed inside each development capusule. 0.D. shrinkage measurements were taken across the stand-off ring nearest the weld. A small increase in capsule length resulted from the weld bead on the end of the capsule (see Table 7 ).

\section{POST-WELD IMSPECTIONI}

All welds received a visual, dye-penetrant, and metallographic inspection. Welds WD-14 through WD-18 received a helium leak check and radiographic inspection. The capsules were acceptable with no defects found. The helium leak rate was less than $1.5 \times 10^{-10} \mathrm{std} . \mathrm{cm}^{3} / \mathrm{sec}$. 


\section{DISCLAIMER}

This report was prepared as an account of work sponsored by an agency of the United States Government. Neither the United States Government nor any agency thereof, nor any of their employees, makes any warranty, express or implied, or assumes any legal liability or responsibility for the accuracy, completeness, or usefulness of any information, apparatus, product, or process disclosed, or represents that its use would not infringe privately owned rights. Reference herein to any specific commercial product, process, or service by trade name, trademark, manufacturer, or otherwise does not necessarily constitute or imply its endorsement, recommendation, or favoring by the United States Government or any agency thereof. The views and opinions of authors expressed herein do not necessarily state or reflect those of the United States Government or any agency thereof. 


\section{I.I I. SUMMARY}

Acceptable GTA welds were made consistently using LWRHU hardware and the enclosed GTA welding parameters (Table 2). Porosity sometimes associated with GTA welds in platinum alloys was not a problem. It was found necessary to machine a small groove in the cap edge to relieve expanded gas created by heat from the weld. The start location of the weld should be 2.0 to $2.5 \mathrm{~mm}(0.08$ inch to $0.10 \mathrm{inch})$ from the groove.

This report includes photomicrographs of a $180^{\circ}$ section and the as-welded condition of a typical capsule. 
TABLE 1

GTA WeTd Shrinkage Data

$\begin{array}{lcc}\text { Capsule No. } & 0 . \dot{D} \text {. Shrinkage, } \mathrm{mm} \text { (inches) } & \text { Length Increase, mm (inches) } \\ \text { WD-11 } & 0.05(0.002) & 0 \\ \text { WD-12 } & 0 & 0.05(0.002) \\ \text { WD-13 } & 0 & 0.05(0.002) \\ \text { WD-14 } & 0.05(0.002) & 0.05(0.002) \\ \text { WD-15 } & 0 & 0.05(0.002) \\ \text { WD-16 } & 0.03(0.001) & 0.05(0.002) \\ \text { WD-17 } & 0.03(0.001) & 0.05(0.002) \\ \text { WD-18 } & 0.03(0.001) & 0.08(0.003) \\ \text { WD-19 } & 0 & 0.03\end{array}$


TABLE 2

LWRHU GTA Weld Parameters

Welding Power Supply - Miller Analog 300, 3 Phase 300 Amp D.C.

Torch Rotation System - Servo-Tek Bi-Mode ST5100-1

Fixture Type - Mound Drawing No. AYC790538

Torch Type - Linde HW-20

Torch Gas Cup Szie - No. 4

Box Gas - Helium

Torch Gas - Aircomatic No. 75 (75\% Helium, 25\% Argon) 20 C.F.H.

Torch Angle and Position - Figures 1 and 2

Torch Gas Preflow - $5 \mathrm{Sec}$

Rotation Speed - 6 Sec per Revoluton

Weld Time - $6.5 \mathrm{Sec}$

Rotation Delay - $0.5 \mathrm{Sec}$

Starting Current - 32 Amperes D.C.S.P.

Upslope Time - 0

Welding Current - 43 Amperes D.C.S.P.

Downslope Time - $0.8 \mathrm{Sec}$

Final Current - 0

Electrode Type $-1.0 \mathrm{~mm}$ (0.040 inch) Dia. 2\% Thoriated Tungsten

Electrode Shape $-3.81 \mathrm{~mm}$ (0.150 inch) Taper with $0.25 \mathrm{~mm}$ (0.010 inch) Rounded Point

Arc Gap - $0.64 \mathrm{~mm}(0.025$ inch $)$. 


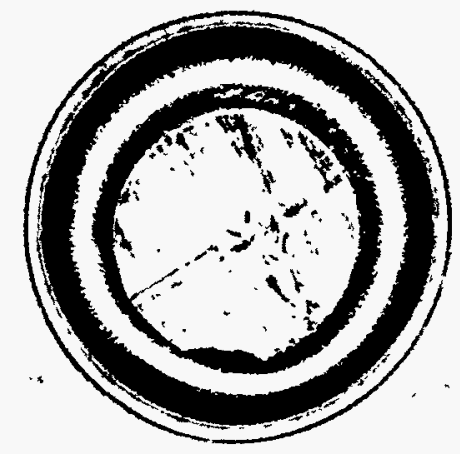

号
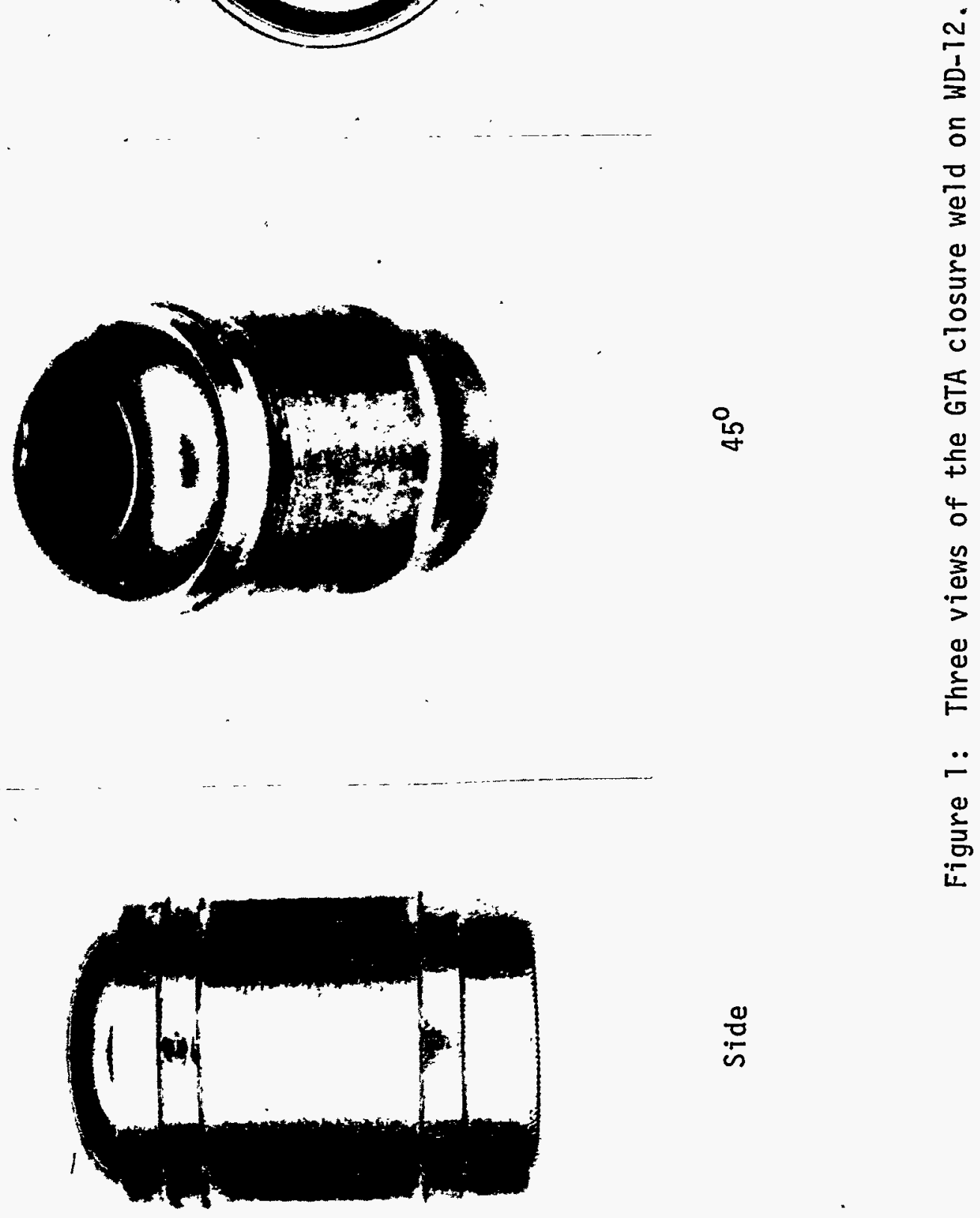

吾 


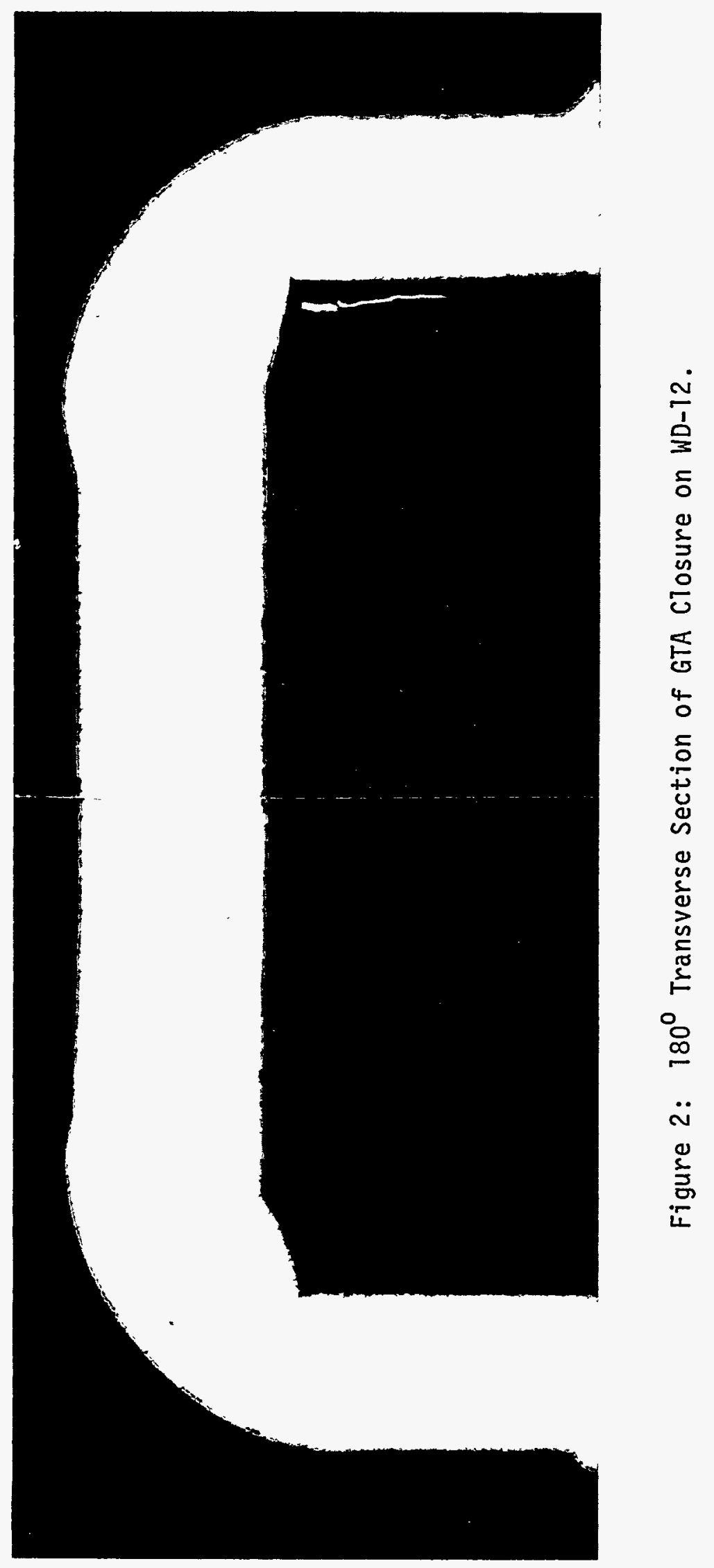




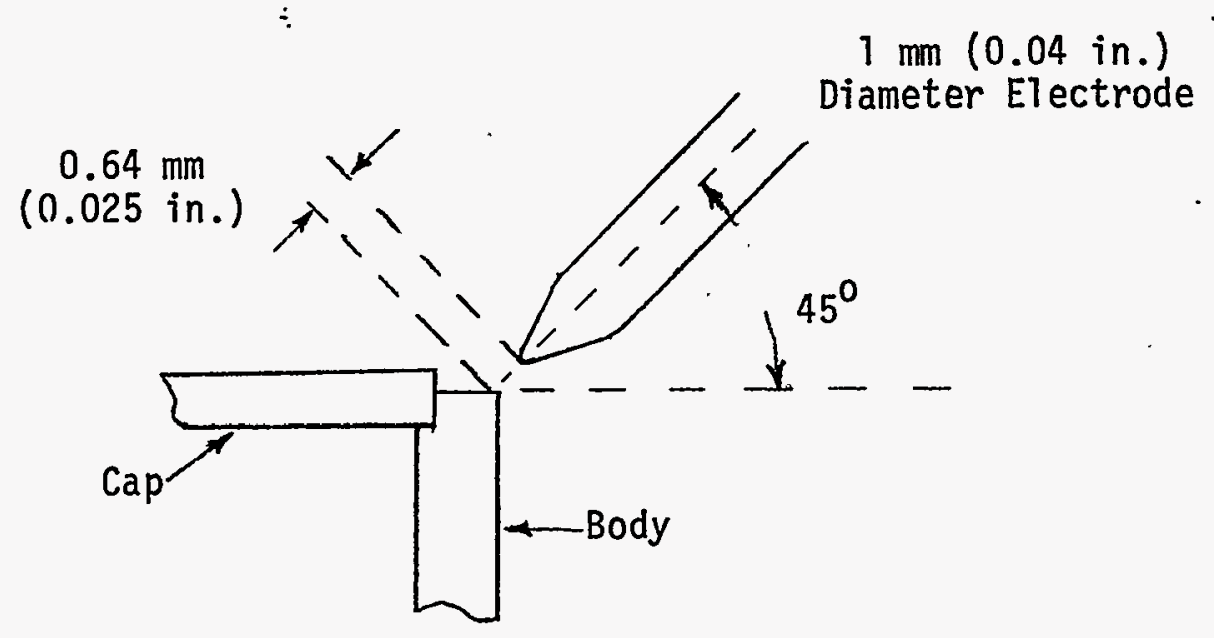

Figure 3: Electrode Position Sketch for GTA Held (Side View).

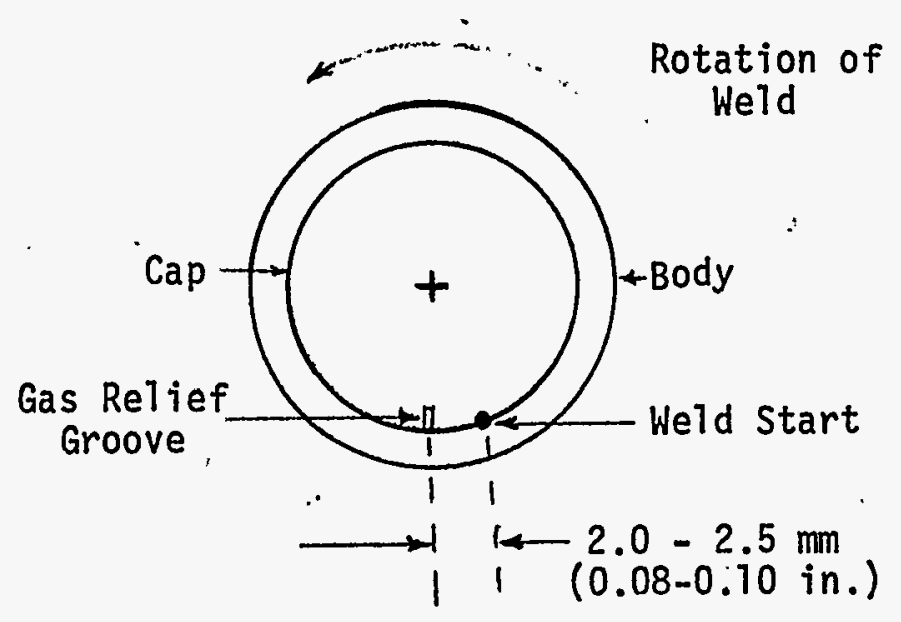

Figure 4: Weld Start Position for GTA Closure Weld. 